\title{
PATRIMÔNIO DO ESCRITO: CADERNOS DE USOS NÃO ESCOLARES E AS CONTRIBUIÇÕES PARA A CULTURA ESCRITA
}

\author{
Vania Grim Thies ${ }^{1}$
}

\section{RESUMO}

O objetivo deste artigo é analisar 55 cadernos de usos não escolares. Tais artefatos foram considerados a partir dos seus conteúdos e receberam 10 diferentes classificações. Como contribuição para o campo da História da Educação, entende-se que os usos dos cadernos com finalidades não escolares abordam uma multiplicidade de registros, tais como, contar o dia, registrar contas, preservar memórias, descrever receitas, entre outras, tornando-se, portanto, um patrimônio do escrito.

Palavras-chave: História da Educação; cultura escrita; patrimônio do escrito; cadernos de usos não escolares.

\section{PATRIMONIO DEL ESCRITO: CUADERNOS DE USOS NOESCOLARES Y LAS CONTRIBUCIONES PARA LA CULTURA ESCRITA}

\footnotetext{
${ }^{1}$ Universidade Federal de Pelotas (UFPEL), Pelotas/RS, Brasil.
} 


\title{
RESUMEN
}

El objetivo de este artículo es analizar 55 cuadernos de usos no escolares. Durante el análisis, tales instrumentos han sido considerados desde sus contenidos y han recibido 10 clasificaciones distintas. Como contribución para el campo de la Historia de la Educación, se comprende que los usos de los cuadernos con finalidades no escolares tratan de una multiplicidad de registros, tales como contar sobre el día, registrar cuentas, preservar memorias, describir recetas, entre otras actividades, volviéndose, por lo tanto, un patrimonio del escrito.

Palabras clave: Historia de la Educación; cultura escrita; patrimonio del escrito; cuadernos de usos no-escolares.

\section{WRITTEN HERITAGE: NON-SCHOOL NOTEBOOKS AND THEIR RELEVANCE FOR WRITTEN CULTURE}

\begin{abstract} memories, describing recipes, and other. They become, therefore, written heritage.

\section{PATRIMOINE DE L'ÉCRIT: CAHIERS D'USAGE NON SCOLAIRE ET LEURS CONTRIBUTIONS POUR LA CULTURE ÉCRITE}

The purpose of this paper is to analyze 55 non-school notebooks. The contents of those artifacts were classified into 10 different categories. Seeking to contribute to the field of History of Education, we conclude that the use of notebooks with no schooling purpose includes multiple records, such as registering what happened during a day, registering accounts, keeping

Keywords: History of Education; written culture; written heritage; non-school notebooks.

\section{RÉSUMÉ}

Le but de cet article est d'analyser 55 cahiers d'usage non scolaire. Tels artefacts ont été considérés en fonction de leurs contenus et ont reçu 10 classifications différentes. Comme contribution pour le champ de l'Histoire de l'éducation, on comprend que l'usage des cahiers pour des fins non scolaires contient une multiplicité de registres, tels que raconter la journée, registrer des comptes, maintenir des souvenirs, écrire des recettes, etc. Il devient, donc, un patrimoine de l'écrit.

Mots-clés: Histoire de l'éducation; culture écrite; patrimoine de l'écrit; cahier d'usage non scolaire. 


\section{À GUISA DE INTRODUÇÕES}

O objetivo principal deste artigo é analisar os usos de cadernos em contextos não escolares ${ }^{2}$, tais como familiares, domésticos, religiosos, entre outros, classificando-os com denominações específicas a partir do conteúdo do próprio material. O estudo foi realizado em um acervo específico, denominado como "escritas pessoais e familiares", salvaguardado no centro de memória e pesquisa Hisales³. Há, nesse referido acervo, 55 cadernos de usos não escolares. Destes, 15 foram usados para a escrita de celebrações religiosas, 6 para a escrita de receitas, 4 para a escrita de recordações, 2 foram utilizados para a escrita de versos e poesias, 3 para a escrita de questionários, 3 para a escrita de músicas, 5 para a escrita de canções, 3 foram usados para a escrita de contas, 13 para a escrita de diários e, por fim, 1 foi utilizado para a colagem de cartões. Assim, os cadernos de uso não escolar foram considerados em 10 diferentes classificações a partir da análise seu conteúdo.

Conceituados como artefatos ou como dispositivos escriturais e escolares (A. CHARTIER, 2007; GVIRTZ, 1999), há um número crescente de pesquisas sendo realizadas com e sobre cadernos escolares 4 , especialmente nos últimos anos. Se, de fato, os cadernos escolares têm sido o foco de diferentes investigações na História da Educação, não é possível afirmar o mesmo para tais dispositivos usados em contextos não escolares. Conforme Viñao Frago (1999, p. 306), "si se pretende saber lo que sucede fuera de la escuela es para entender mejor lo que sucede dentro de ella". Para o estudo aqui apresentado, fazemos

\footnotetext{
2 Para saber mais verificar em HÉBRARD, Jean. Por uma bibliografia material das escritas ordinárias: o espaço gráfico do caderno escolar. In.: Revista Brasileira de História da Educação, $\mathrm{n}^{0}$ 1. Jan./jun. 2001. p. 115-141.

3 O Hisales - História da Alfabetização, Leitura, Escrita e dos Livros Escolares - é um centro de memória e pesquisa vinculado à Faculdade de Educação (FaE) da Universidade Federal de Pelotas (UFPel) e reúne professores pesquisadores, alunos de graduação e de pós-graduação. Para saber mais: wp.ufpel.edu.br/hisales/.

4 Entre os autores estrangeiros estão: Gvirtz (1999), A. M. Chartier (2002; 2007a, 2007b), Hébrard (2001, 2007), Viñao Frago (2008), Meda; Montino; Sani (2010), entre outros. Entre os autores brasileiros podemos citar: Peres (2017), faz um grandioso levantamento dos trabalhos sobre/com cadernos escolares. Aqui cita-se alguns, entre eles: Jacques (2010), Mignot (2005, 2008), Bastos (2008), Becalli (2013), Grazziontin; Gastaud (2010), Cunha (2015), Monteiro (2016), Peres (2012), Monks (2019).
} 
uma afirmação inversa: se já sabemos alguns aspectos sobre o uso escolar do caderno, queremos compreender quais são os seus usos não escolares, tendo em vista a variedade e a multiplicidade de uso desse suporte em diferentes contextos, tais como familiares, religiosos, domésticos, etc.

A investigação dos usos não escolares de cadernos revela outras maneiras e outros interesses, outras competências de escrita e, consequentemente, outros sentidos para a sua prática de uso. Viñao Frago (1999) afirma que as habilidades de leitura e escrita são funcionais para um indivíduo quando se faz o uso por diferentes razões (econômicas, profissionais, ideológicas, etc.). Nesse sentido, apresentam-se os usos plurais dos cadernos em contextos não escolares, demonstrando que as motivações e as funcionalidades desse dispositivo para a escrita são múltiplas, assumindo diferentes sentidos para quem nele escreve.

Problematiza-se o que se faz com a escrita a partir dos usos não escolares desse suporte justamente porque ele foi pensado para ser usado na escola (HEBRÁRD, 2001). Observa-se, a partir dos 55 cadernos analisados neste trabalho, usos não controlados institucionalmente e fora de regras e normas. Para que são usados os cadernos fora da escola? O que as pessoas escrevem nesse suporte? Para que escrevem? Em quais contextos e para quais finalidades são usados? Essas são algumas questões que motivaram a escrita deste artigo.

A prática da escrita em cadernos nos contextos sociais e culturais onde a escola não é a referência como norma demonstra uma variedade de usos, conforme será descrito adiante no texto. Escritas para si, para o controle da vida doméstica, para relembrar, lembrar ou deixar o recado de homenagem, para guardar a receita culinária da família ou, ainda, um texto escrito para ser lido durante a celebração religiosa.

Segundo Certeau (2017), "em história, tudo começa com o gesto de separar, de reunir, de transformar em 'documentos' certos objetos distribuídos de outra maneira" (CERTEAU, 2017, p. 69). Pensar os cadernos não escolares nessa perspectiva, problematizando o seu uso a partir de suas folhas 
desgastadas pelo tempo, foi o primeiro passo deste trabalho historiográfico, seguido da análise com a teoria da cultura escrita. Trata-se de possibilidades que a chamada nova história cultural (Burke, 2011) oferece e que a abertura de novas fontes possibilita no trabalho de pesquisa em história da educação.

No Brasil, os estudos com o tema da cultura escrita vêm sendo desenvolvidos principalmente com as pesquisas de Galvão e demais colaboradores (GALVÃO et al, 2007; GALVÃO, 2010; JINZENJI, GALVÃO, MELO, 2017). Segundo a autora, o conceito de cultura escrita não é isento de polêmicas e não é uma definição simples. Galvão (2010) conceitua cultura escrita partir de uma acepção antropológica:

\footnotetext{
Como toda e qualquer produção material e simbólica produzida a partir do contato dos seres humanos com a natureza, com os outros seres humanos e com os próprios artefatos criados a partir dessas relações, podemos considerar que a cultura escrita é o lugar simbólico e material - que o escrito ocupa em/para determinado grupo social, comunidade ou sociedade (GALVÃO, 2010, p. 218).
}

Nas palavras de Galvão (2010), aquilo que cotidianamente é produzido pelos seres humanos é o que se torna simbólico na vida dos sujeitos, configurando-se como o lugar que o escrito ocupa na comunidade/localidade ou, ainda, para um determinado grupo social. Os usos não escolares dos cadernos demarcam que, além de uma produção material, há também a produção simbólica realizada e preservada por meio da escrita. Tal produção simbólica é, muitas vezes, realizada por pessoas com pouca escolarização que produzem um 'lugar' de guardada/para a escrita, um sentido atribuído para essa prática social com uma maneira de preservá-la como patrimônio familiar, comunitário ou ainda outros.

Chartier (2001), ao discutir a crise do livro e da cultura escrita, indica para "o temor à perda, o que faz com que no século XVI se recolham os textos manuscritos e se multipliquem impressos para assim fixá-los e resgatá-los do esquecimento" (CHARTIER, 2001, p. 21). No referido período, há uma crescente 
multiplicação dos impressos na tentativa de conservar esse "patrimônio escrito", conforme referido pelo autor, a fim de salvá-los do esquecimento. Pensa-se que os cadernos de usos não escolares indicam muito sobre os contextos de sua circulação, quem e o que registram, e, observa-se de forma semelhante que as fronteiras das práticas culturais de leitura e escrita entre os alfabetizados e não alfabetizados, entre popular e erudito, não são tão opostas como muitas vezes é representado.

Em pesquisa realizada com diários de irmãos agricultores da zona rural no sul do Rio Grande do Sul, Thies (2008) investigou os sentidos da escrita de diários na vida de dois irmãos agricultores com pouca escolarização, analisando dezesseis cadernos diários. Nessa pesquisa, afirma que os diários revelam um patrimônio do escrito que 'pode trazer o passado de volta ao presente'. Na conclusão da pesquisa, a autora afirma: "os cadernos são a nossa biblioteca e as escritas desses são os objetos que 'guardam' a história” Ainda em continuidade, "um patrimônio do escrito que nos dá nova significação para as práticas escolares de escrita: a escrita serve, além de tudo, para a vida!" (Thies, 2008, p. 106).

Da mesma forma que a escrita serve, além de tudo, para a vida, podendo-se citar uma variedade de registros e suportes escritos: diários, memórias, receitas, livros de contas, agendas, mesclas de folhas/reportagens coladas com registros escritos, esta prática cultural tem demonstrado também "a possibilidade de uso de variadas fontes escritas para a História" (CUNHA, 2013, p. 252) e, em especial, para a História da Educação.

As palavras de Castillo Gómez (2003) reafirmam que a história da cultura escrita transcende a escrita como mero sistema gráfico para interrogar sobre suas diferentes funções e "las consiguientes prácticas materiales, siempre en referencia a las respectivas sociedades históricas y teniendo en cuenta que en cada momento la sociedad ha estado formada por alfabetizados y analfabetos" (CASTILLO GÓMEZ, 2003, p. 96).

Chartier (2001, p. 84), ao referir-se à tradição italiana da paleografia, 
alerta que a "cultura do escrito vai desde o livro ou o jornal impressos até a mais ordinária, a mais cotidiana das produções escritas, as notas feitas em um caderno, as cartas enviadas, o escrito para si mesmo, etc.”. Chartier (2001) salienta que para além das produções impressas há, também, muito dos registros ordinários na cultura escrita: "parece-me que na cultura do escrito há um continuum desde a prática da escrita ordinária até a prática da escrita literária” (CHARTIER, 2001, p. 84).

\section{OS USOS PLURAIS DE CADERNOS: DISPOSITIVOS PARA USOS NÃO ESCOLARES}

Que rastros as pessoas deixam registrados em cadernos? Esta seção inicia com uma pergunta à procura de respostas. As palavras de Chartier (2014, p. 21) parecem inferir possíveis retornos buscando compreender que "o lugar que a escrita tem ocupado dentro da produção do conhecimento, na troca de emoções e sentimentos, nas relações que os homens e mulheres têm mantido entre si, consigo próprios ou com o sagrado". É nos cadernos de usos não escolares que encontramos uma variedade de respostas para a pergunta anteriormente realizada.

As pessoas com diferentes níveis de escolaridade realizam registros não regrados, cheios de criatividade, recriando possibilidades para o uso do caderno, inicialmente pensado para ser utilizado, não exclusivamente, mas especialmente nas instituições escolares. Conforme apresenta-se neste artigo, um agricultor com uma escassa passagem pela escola utilizou-se do caderno como um diário para contar o feito do dia-a-dia, além de utilizar espaços das folhas para realizar cálculos necessários para os produtos plantados ou colhidos na roça. Apresentam-se, também, cadernos de um pastor utilizados para a escrita das celebrações religiosas. A relação com a leitura, a escrita e a oralidade, para este segundo caso, é uma exigência de maior proximidade com tais habilidades. São exemplos de dois usos de cadernos com finalidades diferenciadas. 
Nesse sentido, passamos a descrever as classificações elencadas nesta pesquisa a partir dos usos dos cadernos como artefatos para a escrita não escolar, para usos não previstos fora desse ambiente, disponíveis no arquivo do centro de memória e pesquisa Hisales, especialmente em um dos seus seis acervos principais: o acervo das escritas pessoais e familiares.

As classificações descritas foram realizadas a partir do conteúdo dos cadernos. Tal análise e classificação exigiu um olhar cuidadoso em cada artefato e em seu conteúdo, por vezes, não sendo possível verificar, enfim, o contexto específico e único de seu uso porque a análise indicou contextos variados. $\mathrm{Na}$ totalidade, foram verificados 55 cadernos não escolares, os quais foram considerados segundo 10 diferentes classificações levando em conta seus conteúdos. A opção por descrever cada uma busca contrapor a escrita escolar, quase sempre submetida a regras e/ou aprendizagens formais da escrita nesse ambiente. Afinal, também se escreve para além da escola, mesmo considerandoa como a principal agência responsável pelo ensino de tal aprendizagem.

A seguir, apresentam-se as 10 classificações realizadas a partir do conteúdo dos cadernos: caderno de celebrações religiosas, cadernos de receita, cadernos de recordações, cadernos de versos e poesias, cadernos questionários, cadernos de músicas, cadernos de canções, cadernos de contas, cadernos de diários pessoais, cadernos de cartões. Em muitos, há um hibridismo na composição das folhas, com uma mistura entre a escrita manuscrita e colagens retiradas de jornais, revistas, escritas e colagens de cartões, escritas e colagens de imagens.

\section{CADERNOS DE CELEBRAÇÕES RELIGIOSAS}

Os manuscritos são referentes à preparação das celebrações religiosas 5 ,

5 Os cadernos de celebração religiosa analisados são de instituições religiosas vinculadas à diferentes vertentes do luteranismo: Sínodo de Missouri, atualmente chamada de Igreja Evangélica Luterana do Brasil (IELB), Sínodo Rio-grandense, atualmente chamada de Igreja 
tais como: cerimônia de casamentos, cultos, batizados, confirmações, mortes, etc. $\mathrm{O}$ que indica o seu uso para conteúdo religioso são enunciados referentes aos "prezados ouvintes" ou "prezada comunidade" e, além disso, passagens bíblicas relacionadas com reflexões que seriam enunciadas oralmente no dia da celebração.

Trata-se de um conjunto de 15 cadernos de diferentes anos e décadas (1942, 1961, 1966, 1973, 1974, 1978, 1978, 1979, 1989, 1992), alguns não apresentam data e, ainda, um deles foi utilizado por mais de um ano compreendendo o período de 1996 a 2004. Destes materiais, 8 são de uma mesma pessoa que escreveu cadernos de celebração em língua portuguesa e também cadernos em língua alemã. As capas de alguns dos cadernos indicam a finalidade do artefato para uso escolar (figura 01), no entanto, é utilizado com outra finalidade: escrever os cerimoniais religiosos.

Figura o1 - Capa do caderno de celebração religiosa (1966)

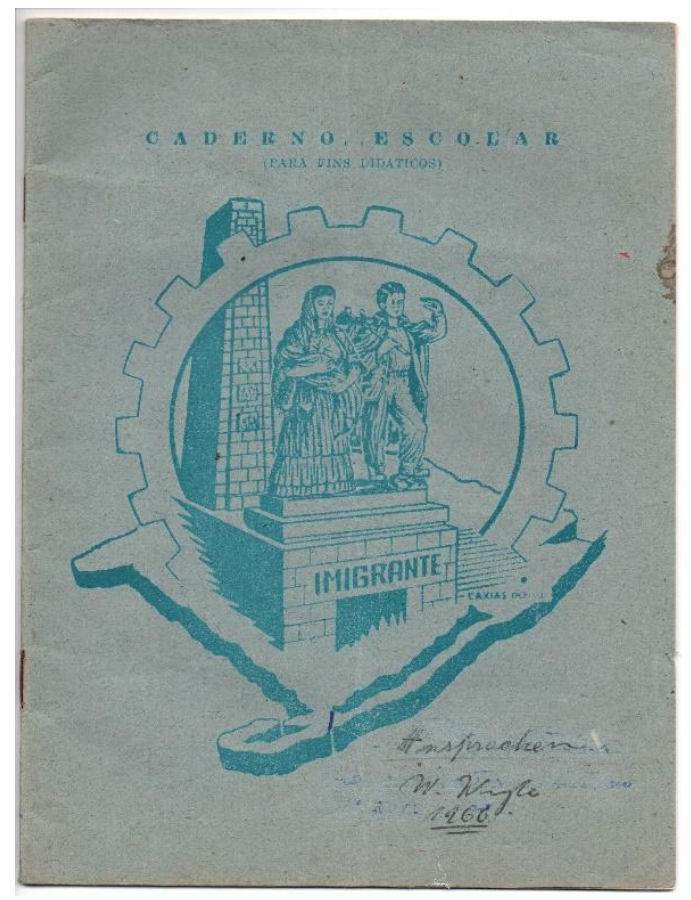

Evangélica de Confissão Luterana no Brasil (IECLB) e, ainda, Igreja Evangélica de Confissão Luterana Independente (IECLBI). Para saber mais sobre o tema, ver Weiduschadt (2007) e Weiduschadt; Tambara (2012). 
Fonte: Hisales

O termo 'Caderno Escolar para fins didáticos' é o indicativo explícito para o uso na escola, no entanto, para o caso aqui apresentado, foge deste contexto e do conteúdo escolar, demonstrando a mobilidade e circulação do artefato em outros espaços. Chartier (2014, p. 29) afirmou que a "a conexão entre experiência religiosa e os usos da escrita constitui outro fenômeno essencial”. Certamente porque a escrita está presente em vários momentos (antes e durante) das celebrações religiosas. Nos manuscritos dos cadernos de celebração, há várias passagens que são reescritas, riscadas ou completadas a lápis com mais algumas ideias após uma suposta leitura realizada. Escrever, ler, revisar e, a partir disso, incorporar novos fatos ou palavras a serem ditas durante a celebração, parece bastante recorrente na prática de escrita desses cadernos de celebração. Uma relação entre a escrita do caderno e a oralidade que é expressa a partir do que está registrado nele. Essa abordagem entre a oralidade e escrita merecerá um artigo à parte e não será tratada aqui.

\section{CADERNOS DE RECEITA}

Produzidos por mulheres, geralmente antes do casamento, foram e ainda são uma maneira de organizar o ritual de cuidado a elas destinado: o espaço doméstico. No já referido acervo há 6 cadernos de receita. Destes, 2 (um do ano de 1985 e outro do ano de 2007) reúnem receitas manuscritas e outras recortadas e coladas nas suas páginas, demonstrando uma mescla entre o manuscrito e impresso.

Outros 2 cadernos (sem identificação de data) contêm receitas impressas com espaços livres para a escrita/cópia de demais receitas. Considera-se cadernos de 'modelos' prontos para a continuidade de escritas dessas prescrições. No entanto, há ainda outros 2 cadernos, dos anos de $1987 \mathrm{e}$ 1990/1991, que apresentam somente receitas manuscritas. Quando há colagens, 
são apenas de figuras ilustrativas como uma maneira de decoração de algumas páginas. Seriam essas receitas manuscritas, aprendizagens repassadas entre as gerações de uma mesma família? Possivelmente sim, mas os referidos documentos não fornecem pistas para tais argumentos. Esses dois cadernos diferem-se dos demais porque além de conter todas as receitas manuscritas, suas últimas folhas apresentam outros tipos de registros, como é o exemplo de um verso:

\author{
Amar e não ser amado \\ Destinado que Deus me deu \\ Amar o amor dos outros \\ Sabendo que não é meu (Caderno de receita, 1987).
}

O espaço doméstico pode ser um lugar destinado às confissões, à escrita do íntimo e, ao escrever ou ler uma receita, pode nascer a necessidade de expor sentimentos no papel. Neste caso, o caderno de receitas torna-se também um suporte disponível para demais escritas, como os registros de si. Conforme trabalho de Mignot; Bastos e Cunha (2000, p. 17), ao referirem-se à imagem de uma rapariga escrevendo ${ }^{6}$,realizam questionamentos:

\footnotetext{
Registra para encobrir sua solidão ou para expressar seus sentimentos ocultos, confessar sonhos desfeitos, conferir sentido às vivências mas significativas e exercitar a liberdade de construir a si mesma através da escrita? A imagem da 'Rapariga escrevendo' sugere que ao se debruçar sobre os papéis ela se debruça sobre si mesma (MIGNOT; BASTOS; CUNHA, 2000, p. 17).
}

Escrevendo sobre si mesma, construindo uma identidade feminina entre receitas e outras confissões. Entre a consulta de uma receita, há também a necessidade de uso do caderno para outras questões. Nas páginas finais há

\footnotetext{
${ }^{6}$ Gravura do século XIX que ilustra a capa do livro das autoras. MIGNOT; BASTOS; CUNHA (Org.). Refúgios do eu: educação, história e escrita autobiográfica. Florianópolis: Mulheres, 2000.
} 
pequenos trocadilhos com nomes próprios, alguns cálculos e demais escritas pessoais, tais como as confissões de um final de semana registrado, possivelmente, por uma adolescente:

Hoje 6-07-87 estou olhando o jornal nacional são 8 e 15 esse fim de semana tava tão bom namorei todo o fim de semana sábado e domingo. Segunda-feira" ${ }^{7}$ (Caderno de receita, 1987).

Mesmo quando o caderno tem um destino tal como o dito acima, para a escrita de receitas, o artefato foge a suas regras de registro e passa a registrar outros aspectos da vida, tais como os sentimentos e as reflexões sobre si, extrapolando a finalidade primeira do caderno que, para o caso descrito, seria o da escrita de receitas.

\section{CADERNOS DE RECORDAÇÕES}

Também nomeados de álbuns de poesia e recordação (CUNHA, 2011), "eram uma forma ritual de prestar homenagens escritas que foram bastante frequentes, desde os finais do século XIX até os anos 60 do século XX" (CUNHA, 2001, 347). Os cadernos de recordação circulavam na escola paralelamente aos cadernos de aprendizagem de tarefas escolares, no entanto, com finalidades diferenciadas: um para registro de atividades de aula e, outro, com o objetivo da "expressão da afetividade escolar" (CUNHA, 2001, p. 352). Dessa forma, podemos perceber que os cadernos possibilitam outros registros ordinários e paralelos dentro do próprio ambiente escolar.

As capas contêm inscrições tais como: Poesias, Caderno de Poesias, Caderno de recordação, indicando diferentes nomenclaturas para tal finalidade da escrita de recordações, embora, consideramos aqui, como caderno de

\footnotetext{
$7 \mathrm{O}$ registro foi mantido conforme estava escrito no caderno, sem correções ortográficas ou modificações na estrutura.
} 
recordação a partir do acervo pesquisado, apenas aqueles em que houve a circularidade deste artefato, ou seja, consideramos os cadernos cujos registros foram realizados por diferentes sujeitos e endereçados para o "proprietário" do caderno. Para realizar a classificação, foram analisados 4 cadernos de recordação referentes aos anos de 1947-1988; 1949; 1959 e 1965-1969. Todos pertenceram a mulheres, porém, há também registros realizados por meninos, jovens homens à época, e endereçados a elas.

$\mathrm{Na}$ folha de abertura, um registro revela o pedido para a guarda das memórias juvenis:

Peço as minhas gentis amiguinhas e amiguinhos para deixarem nas páginas deste álbum, um soneto para quando no futuro...um dia... ao folha-lo encontre algo que me faça lembrar a nossa bela juventude. Agradecida (L. M. R., Pelotas, 1949).

Em cada um dos cadernos de recordação, há registros de mais de um ano civil, demonstrando que era uma prática planejada para ser escrita em diferentes momentos e não apenas em um único ano. Em um dos cadernos, há folhas que não foram preenchidas, mas há a indicação de nomes, escritos a lápis, que supostamente deveriam ter realizado o registro. São escritas pessoais com os registros de 'bons desejos' para a juventude, carregadas de afetos e sentimentos materializados em pequenos versos. Ao final de cada uma encontra-se a data do registro e o nome de quem escreveu, tal como é possível verificar no excerto que segue:

Amiga, que todos os teus sonhos sejam realizados. Para que tua existência seja clara e risonha como o despertar de um dia primaveril. E que no futuro desta existência eu seja incluída na lembrança e na saudade (M. C. L; 1968).

O desejo da guarda da memória é sempre uma marca presente, perceptível nos enunciados ao longo da escrita: 'sonhos sejam realizados', 
'lembrança', 'saudade’.

\section{CADERNOS DE VERSOS E POESIAS}

Os cadernos classificados de versos e poesias se diferenciam dos cadernos de recordação porque esses dispositivos não circulavam para que outras pessoas pudessem realizar escritas. Sua finalidade era a de um registro de si (GOMES, 2004) e também para si, como se fosse uma forma de dialogar silenciosamente com o 'eu'. Exprimir o eu seria o objetivo desses cadernos com seus versos, frases e poemas? Nas palavras de Ranum (2009, p. 212), "é evidente que o eu pode exprimir-se por meio de um parágrafo, de uma assinatura, de um lema”, tal como é possível verificar nesses suportes.

No acervo pesquisado, há apenas dois cadernos dessa classificação. Um deles é denominado de "Cadernos de pensamentos" na primeira folha e contém pequenos versos e poemas manuscritos, em sua grande maioria. Frases do pintor espanhol Pablo Picasso, do líder indiano Mahatma Gandhi, poemas de Mário Quintana e Carlos Drummond de Andrade, entre outros, são alguns que aparecem manuscritamente copiados no caderno. É importante destacar que há registros assinados pela pessoa a quem o caderno pertenceu, ou seja, escritos autorais demarcando momentos pessoais em forma de poemas e frases. Há registros dos anos de 1985 a 1994. Há, também, versos e poemas que foram recortados de jornais e colados nas folhas do caderno. Ainda, contém cartões de aniversário e de demais datas comemorativas (Natal, dia dos professores) fixados nos cantos permitindo a sua retirada para a leitura. No diálogo com o eu, em meio aos poemas e frases, infere-se que, pela diversidade de datas, os cartões revelam a vontade de guardar algo disperso no tempo.

O outro caderno de versos e poesias data do início dos anos 1980. Assemelha-se ao primeiro, com versos, poemas, frases sobre 'o amor', porém, não há assinaturas nem indicativo de nome a quem pertenceu. Seus registros alternam-se entre manuscritos e colagens de imagens e poemas. 


\section{CADERNO DE QUESTIONÁRIO}

A denominação do caderno 'questionário', já na primeira folha, indica sua classificação própria, caracterizado por perguntas diretas e respostas simples. Demarcam um período juvenil, com o registro por meio de brincadeiras, assinaturas, nomes de pretendentes e namorados, entre outros aspectos que são identificáveis nos registros.

No acervo consultado, há três cadernos questionários: um do ano de 1977 e dois do ano de 2005. Para cada período histórico, as questões diferem-se: "Pretendes casar com teu broto?", "Quais as músicas que mais gostas?”, “Gostarias de viajar de avião?", são alguns dos questionamentos do caderno do ano de 1977. Já os cadernos questionários do ano de 2005 apresentam perguntas tais como: "você acredita em amor à primeira vista?". Na sequência, a pergunta continua: "E se for por via celular", entre outras, reveladores das preocupações juvenis: "Você continuaria sendo a mesma pessoa sabendo que seu melhor amigo tem AIDS?" e "O que você acha de Deus?". Para os diferentes períodos históricos, mudam-se as perguntas, mas o caderno como suporte para o questionário permaneceu entre as diferentes gerações.

Os questionários funcionavam como uma espécie de brincadeira entre os adolescentes com a disputa para escrever e uma grande curiosidade para realizar a leitura de cada resposta. Sua circulação, semelhante aos cadernos de recordação, eram frequentes nas escolas, ao lado dos demais materiais escolares. Porém, a circularidade e o seu uso não era algo visibilizado pelos professores, ou seja, cadernos de recordação e de questionário estavam ao lado dos cadernos de aprendizagem das lições escolares. O que os diferenciava? A escrita como controle e como uma regra escolar.

\section{CADERNOS DE MÚSICA}

No acervo pesquisado há três cadernos de música dos anos de 1955, 
1956 e um sem registro de data (s/d). Nestes, os registros são da letra de músicas com os seus respectivos solfejos. Os três suportes apresentam na capa a indicação que são para essa finalidade: 'Caderno de Música' e 'Livro de Música', apresentando ainda linhas específicas para essa escrita nas folhas internas.

Os três cadernos apresentam letras de músicas, em sua maioria escritas em língua alemã e de cunho religioso, indicando seu contexto de uso. Um dos registros indica, ainda, o dia mais propício para o uso da música, o dia da 'Santa Ceia, conforme é possível observar na figura 02:

Figura o2: Folha do caderno de música (1955

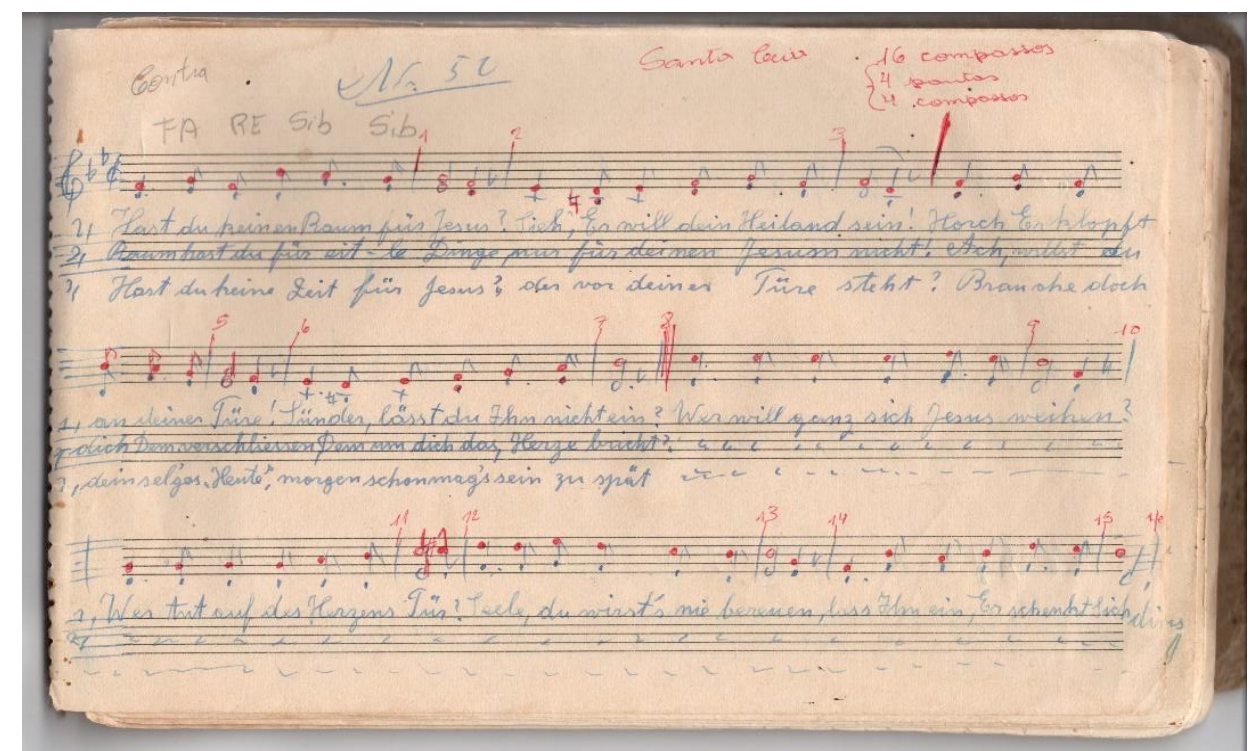

Fonte: Hisales

Além disso, foi possível realizar o cruzamento de informações dos cadernos não escolares nas doações no acervo pesquisado e verificou-se que um desses cadernos de música também pertenceu ao pastor já referenciado 
anteriormente na análise dos cadernos de celebração, reforçando para essa classificação (caderno de música) o seu uso no contexto religioso.

A análise da caligrafia e também a cor da caneta utilizada indica que o caderno foi usado por pessoas diferentes e, possivelmente, perpassando diferentes períodos e/ou gerações familiares. Um aspecto que chama atenção é a numeração de cada letra de música, permanente em todo o caderno. Certamente, era uma garantia de que, para além da organização das músicas e da continuidade dos registros, servia para "verificar se nenhuma página foi arrancada" (HÉBRARD, 200o, p. 37).

\section{CADERNOS DE CANÇÕES}

Tratam-se de cinco cadernos pequenos sem registro de datas nas folhas. Serão chamadas de cadernetas devido ao seu formato. Das cinco, duas delas apresentam o registro manuscrito de pequenos cânticos religiosos e populares. Ainda, há o hino nacional e hino à bandeira misturados aos demais cânticos. Uma terceira caderneta apresenta modelo bastante semelhante às duas primeiras, porém todas as canções estão escritas em língua alemã.

Outra caderneta apresenta uma variedade maior de cânticos com letras referentes às datas comemorativas (Páscoa e dia das mães). Há várias folhas em branco e é nessas em que há uma variedade de registros que fogem da proposta desta classificação, ou seja, não há cânticos, mas sim, outros registros tais como: adivinhações, endereços, medidas de roupas, bilhete, anotações em língua alemã.

Fugindo à regra da escrita apenas de cânticos, por fim nessa classificação, há uma quinta caderneta contemplando uma mescla de cânticos e com o registro de contas nas folhas finais, indicando o pagamento de produtos, tais como sacos e latas de batata, quilos de feijão, toucinho em quilos e demais produtos coloniais. Foi possível encontrar uma pequena foto (3x4) de uma 
pessoa e um anúncio impresso de orientação espiritual. Optamos por manter essa caderneta na classificação dos cânticos porque é o gênero de texto presente em grande maioria nela, mais do que as próprias anotações das contas.

\section{CADERNO DE CONTAS}

São cadernos que registram somente contas referentes à vida doméstica. Encontram-se no acervo pesquisado três cadernos de contas (um deles é um caderno pequenino, portanto, uma pequena caderneta).

No primeiro caderno de contas aqui descrito, há registros sistemáticos do ano de 1927, organizados em meses do ano com nomes de produtos, quantidades e preços, semelhante ao controle de vendas. Todos os registros deste caderno estão em língua alemã.

No segundo caderno de contas, há poucas folhas. Todas estão com nomes de pessoas e com anotações que utilizam apenas numerais, sem outras palavras que pudessem fornecer mais dados sobre seu contexto de uso. Como não há contas ou preços, semelhantes aos outros dois cadernos de contas do referido acervo, é possível tomar as palavras de Hébrard (2000, p, 39) para pensar sobre ele, quando afirma que "prestar contas de suas despesas ou de sua vida são atos próximos e que progressivamente se confundem”.

O terceiro caderno, muito pequeno, ao que se denominou de caderneta, remete ao registro de um jovem agricultor que iniciou suas anotações quando começou o serviço militar, em 1942, e que perduraram até, pelo menos, 1952. Em outra produção realizada a partir desse livro de contas, Thies e Peres (2017) afirmam que se trata de uma escrita escassa, "por vezes apresenta apenas o ano, sem registro pormenorizado de data. O pequeno livro de contas serviu, entre outras coisas, para as anotações dos ganhos do soldado no período em que esteve no quartel”. E, ainda, para registros de nomes e alguns endereços. 


\section{CADERNOS DE DIÁRIOS PESSOAIS}

No acervo pesquisado, a tipologia dos diários abrange treze cadernos. O maior número de cadernos utilizados como diários é referente às escritas de um agricultor, homem que escreve diários ${ }^{8}$, totalizando nessa classificação oito cadernos correspondentes aos anos de 1968 a 1976 (em cinco cadernos escritos ininterruptamente) e de 1982 a 1986 (mais três cadernos escritos ininterruptamente). Além dos diários desse agricultor, há outro caderno diário escrito por uma senhora, atualmente agricultora aposentada, de 85 anos e, ainda, mais quatro diários escritos por diferentes autores, em períodos históricos também diferenciados.

Dias de passeio, dias de trabalho, variações climáticas, venda de produtos, jogos de futebol, preços, contas...há uma variedade de registros nos diários. A vida cotidiana é imersa destas variedades, tais como é possível verificar no excerto que segue:

3-6-74: Fui na namorada Seleção 2 a 1 Era calor.

Um passeio na casa da namorada, um jogo da uma seleção de futebol (provavelmente da Copa do Mundo, pelo registro da data) e, ainda a referência ao clima. Prestar contas para si constitui-se de um ato ético e estético de deixar a vida por escrito (THIES, 2008, 2013). Contar o dia com essa variedade de atividades faz parte da prática, entre outras tantas, atribuída por convenção às mulheres (PERROT, 1989). No entanto, o exemplo demonstra uma contrariedade à regra, pois destaca-se o caso de um homem que escreveu 8 diários, utilizando para isso os cadernos como dispositivo para tal escrita.

\footnotetext{
8 Para saber sobre o tema da escrita masculina de diários ver em Thies (2008; 2013).
} 


\section{CADERNO DE CARTÕES}

Essa classificação foi a que mais distinguiu-se das anteriores. Não há nenhum registro manuscrito nas suas folhas, nem ao menos registros de locais ou datas. Trata-se de um caderno que contém diversos tipos de cartões colados em suas páginas: de casamento, postais, de bons desejos de final de ano, de propagandas, de aniversários, entre outros. As datas foram averiguadas a partir dos próprios cartões colados e são de anos diferentes: 1899 (faz-se aqui uma ressalva para o registro do século XIX), 1900, 1901, 1902, 1904, 1905, 1906, entre outras datas. Na variedade de cartões colados em cada página do caderno os que mais chamam a atenção são os cartões postais, bastante variados: há imagens da capital do Rio Grande do Sul, Porto Alegre, e de cidades do interior do estado do Rio Grande do Sul, com imagens urbanas e rurais (Pelotas, Piratini, São Lourenço do Sul, Rio Grande). Além disso, os cartões postais apresentam imagens do estado do Rio de Janeiro, bem como algumas cidades de outros países, tais como Paris, por exemplo. A figura 03 demonstra a organização dos cartões nas páginas do caderno. 
Figura 03: Folha interna do caderno de cartões

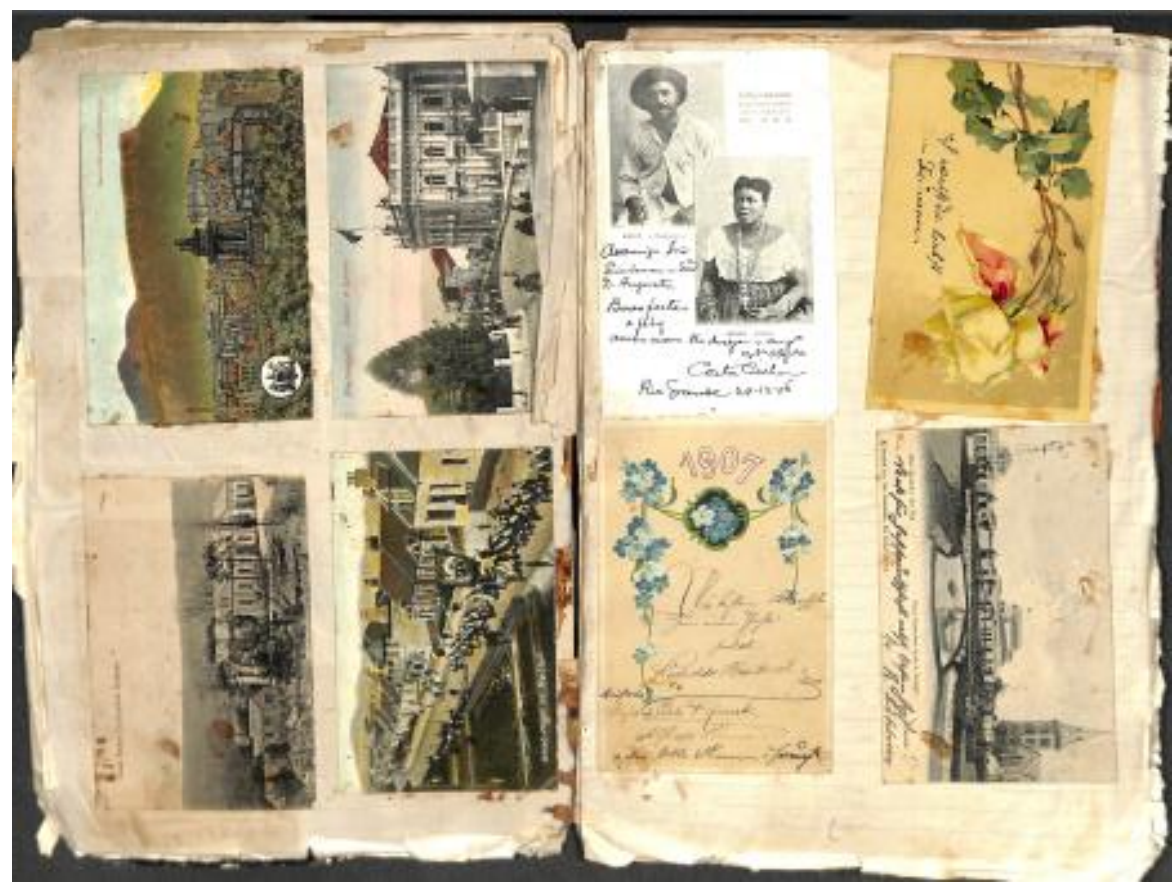

Fonte: Hisales

A ficha de doação do caderno para o acervo pesquisado indica que ele pertenceu a uma família moradora do interior de um município da região sul do Rio Grande do Sul. Tal família possuía um comércio que era referência naquela localidade, ou seja, comercializava grãos, mantimentos, tecidos entre outros diversos artigos para as famílias da zona rural. Tendo em vista que muitos cartões indicavam 'bons desejos para o ano novo' em anos variados, infere-se que a família ganhava cartões dos viajantes que por ali passavam e eram fornecedores dos artigos para o referido comércio.

O caderno parece-nos uma forma de arquivar os objetos-relíquias (RANUM, 2009) para evitar o esquecimento ou a perda dos cartões. O uso do caderno para essa finalidade de colar cartões possibilitou uma preciosa guarda 
desses artefatos. Considera-se que a guarda dos cartões colados no caderno foi uma forma de preservar tanto os próprios cartões, como também o próprio artefato caderno, resguardando-os do descarte.

\section{À GUISA DE CONCLUSÕES}

A partir da classificação de usos plurais dos cadernos não escolares é possível identificar que eles circulam em três esferas principais: a familiar, a doméstica e a religiosa. Outra esfera possível seria, também, a escolar. No entanto, não como uso para registro das atividades escolares, mas para outros, como é o caso dos cadernos de recordação e dos cadernos questionários.

Todos os materiais apontam que há uma variedade de práticas de escrita tendo o caderno como seu suporte. Destacam-se, a partir dos artefatos de uso fora do ambiente escolar, os diferentes níveis e competências de escrita para diferentes finalidades: o caso do agricultor, com pouco tempo de permanência na escola, que utilizou-se de cadernos para contar sobre seus dias a partir do gênero diário; o pastor, com uma maior proximidade com a leitura e a escrita por exigência da sua profissão, fez do uso de cadernos com o registro dos cerimoniais para leitura durante as celebrações religiosas, e, ainda, os cadernos de contas com sistematizações de cálculos (e não só delas) e demais anotações, conforme demonstrado ao longo do texto.

Trabalhar com cadernos de usos não escolares é uma tarefa um tanto difícil porque, para realizar suas classificações, muitas vezes não há um ponto de demarcação entre um registro e outro, entre a intencionalidade no começo e no término de um caderno. As práticas de escrita escapam às classificações utilizadas, percorrem outros trajetos não sinalizados, mesmo quando apontado na folha de abertura o seu destino, tal como no exemplo do caderno de receitas que serviu para registrar os sentimentos de um final de semana. Ao tomar esse exemplo, percebe-se que não encontramos apenas a escrita das receitas nesses cadernos, mas também encontramos bilhetes, anotações de nomes e outros 
manuscritos que fogem da suposta 'regra' de receitas culinárias. Encontramos também nos cadernos de cânticos mais exemplos dessas fugas, quando há, para além das folhas com os cânticos, perguntas com adivinhações, medidas de roupas, endereços, entre outras anotações.

É importante ressaltar que os cadernos de usos não escolares como patrimônio do escrito tomam esse status quando preservados do fogo e do lixo, entre as diferentes gerações, até chegar a uma instituição de salvaguarda para que o patrimônio seja institucionalizado e reconhecido servindo também para pesquisas que visibilizem o potencial dos cadernos não escolares e das práticas de escrita fora da escola. Os usos desses cadernos revelam um patrimônio do escrito justamente na imprevisibilidade das escritas, nos 'desvios' e na criatividade das pessoas que nele escrevem, não seguindo regras ou formalidades estabelecidas, como são os exemplos dos cadernos de receitas, de música, entre todos os outros demonstrados no artigo.

Considerando os usos não escolares dos 55 cadernos, nas 10 diferentes classificações, "não faltam fontes para uma pesquisa sobre os suportes das escrituras (HÉBRARD, 2000, p. 29). Dessa forma, pensa-se o quanto a vida cotidiana ainda está por ser narrada no campo da História da Cultura Escrita e na História da Educação.

\section{REFERÊNCIAS}

BASTOS, Maria Helena Camara. Relíquias escolares: uma vida em cadernos. Um campo de pesquisa da cultura escolar. In: PASSEGGI, Maria da Conceição; SOUZA, Elizeu C. de; ABRAHÃO, Maria Helena (Org.). Pesquisa (Auto)Biográfica e práticas e formação. Natal: Editora Paulus; EDUFRN, 2008.

BECALLI, Fernanda Zanetti. Nos cadernos escolares de um passado recente: uma história do ensino da leitura no estado do Espírito Santo (2001 a 2008). 2013. 282 f. Tese (Doutorado em Educação) Programa de PósGraduação do Centro de Educação da Universidade Federal do Espírito Santo. 
Universidade Federal do Espírito Santo/UFES. Vitória. 2013.

BURKE, Peter. Abertura: a nova história, seu passado e seu futuro. IN: BURKE, Peter (Org.). A escrita da história: novas perspectivas. São Paulo: Editora Unesp, 2011. p. 07-38.

CASTILLO GÓMEZ, Antonio. Historia de la cultura escrita: ideas para el debate. In.: Revista Brasileira de História da Educação, $n^{0}$ 5. Jan./jun. 2003. p. 93-124.

CUNHA, Maria Teresa Santos. Copiar para homenagear, guardar para lembrar: cultura escolar em álbuns de poesias e recordações. In: STEPHANOU, Maria; BASTOS, Maria Helena Câmara (Orgs.). Histórias e memórias da educação no Brasil, vol. III. Petrópolis, RJ: Vozes, 2011. p. 347-362.

CHARTIER, Anne-Marie. Um dispositivo sem autor: cadernos e fichários na escola primária. Revista Brasileira de História da Educação. Campinas, n. 3, p. 9-26, jan./jun. 2002.

CHARTIER, Anne-Marie. Exercícios escritos e cadernos de alunos: reflexões sobre as práticas de longa duração. In: CHARTIER, Anne-Marie. Práticas de leitura e escrita. História e atualidade. Belo Horizonte: Autêntica, 2007a. p.21-66.

CHARTIER, Anne-Marie. Os cadernos escolares: organizar os saberes escrevendo-os. Revista de Educação Pública. Cuiabá, v.16, n. 32, 2007b. p. 13-33.

CHARTIER, Roger. Cultura Escrita, literatura e história: conversas de Roger Chartier com Caros Aguirre Anaya, Jesús Anaya Rosique, Daniel Godin e Antonio Saborit. Porto Alegre: Artmed Editora, 2001.

CHARTIER, Roger. A mão do autor e a mente do editor. Trad. George Schlesinger. São Paulo: Editora Unesp, 2014.

DE CERTEAU, Michel. A escrita da História. Rio de Janeiro: Forense, 2017.

HÉBRARD, Jean. 200o. Por uma bibliografia material das escrituras ordinárias: a escritura pessoal e seus suportes. In: MIGNOT; BASTOS; CUNHA (Org.). Refúgios do eu: educação, história e escrita autobiográfica. Florianópolis: Mulheres, 2000. p. 29-61.

HÉBRARD, Jean. Por uma bibliografia material das escritas ordinárias: o espaço gráfico do caderno escolar. In.: Revista Brasileira de História da Educação, $n^{0}$ 1. Jan./jun. 2001. p. 115-141. 
JACQUES, Alice Rigoni. Cadernos escolares - relíquias de memórias. In.: Encontro da Associação Sul-Rio-Grandense de Pesquisadores em História da Educação (ASPHE), 16. 2010, Porto Alegre. Anais... Porto Alegre: UFGRS, 2010. p. 1-15

GALVÃO, Ana Maria de Oliveira. Histórias das culturas do escrito: tendências e possibilidades de pesquisa. In.: MARINHO, Marildes; CARVALHO, Gilcinei Teodoro (Org.). Cultura escrita e letramento. Belo Horizonte: Editora UFMG, 2010, p. 218-248.

GALVÃO, Ana Maria de Oliveira et al. (orgs.). História da Cultura Escrita: séculos XIX e XX. Belo Horizonte: Autêntica Editora, 2007.

GOMES, Angela de Castro. Escritas de si, escrita da história: a título de prólogo. Rio de Janeiro: Editora FGV, 2004.

GVIRTZ, Silvina. El discurso escolar a través de los cuadernos de clase. Argentina (1930 - 1970). Buenos Aires: Eudeba, 1999.

JINZENJI, Mônica Yumi, GALVÃO, Ana Maria de Oliveira, MELO, Juliana Ferreira de. (orgs.) Culturas orais, culturas do escrito: intersecções. 2017. Campinas: Mercado de Letras, 2017.

MEDA, Juri. MOONTINO, David. SANI, Roberto. School exercice books - A complex source for a history of the approach to schooling and education in the 19th and 2oth centuries. Florence: University of Macerata; National Agency for the development of School Autonomy; Edizioni Polistampa, v.1, v.2, 2010.

MIGNOT, Ana Chrystina Venancio. Por trás do balcão: os cadernos da coleção cívica da Casa Cruz. In: STEPHANOU, Maria; BASTOS, Maria Helena Camara (Org.). Histórias e memórias da educação no Brasil, vol. III. Petrópolis, RJ: Vozes, 2005. p. 365-378.

MIGNOT, Ana Chrystina Venancio; VEIGA, Roberta. Um Rio para estudante ver: engenhosidades na produção de cadernos escolares. Revista História da Educação, v. 12, n. 24, p. 225-247, 2008.

MIGNOT, Ana Chrystina Venancio; BASTOS, Maria Helena Câmara; CUNHA, Maria Teresa Santos. Tecendo Educação, História, Escrita autobiográfica. In.: MIGNOT; BASTOS; CUNHA (Org.). Refúgios do eu: educação, história e escrita autobiográfica. Florianópolis: Mulheres, 2000. p. 17-27.

MONKS, Joseane Cruz. Do artesanal ao digital: uma genealogia dos meios de produção e reprodução de folhinhas de atividades em cadernos de alunos. 
2019. 151 f. Dissertação (Mestrado em Educação) - Faculdade de Educação/FaE

- Universidade Federal de Pelotas/UFPEL, Pelotas. 2019.

MONTEIRO, Carolina. Ditado: concepções, orientações e práticas de um dispositivo escolar (1939 - 1971). 2016. 206 f. Tese (Doutorado em Educação). Faculdade de Educação. Universidade Federal do Rio Grande do Sul, Porto Alegre. 2016.

PERES, Eliane. Um estudo da história da alfabetização através dos cadernos escolares (1943-2010). Cadernos de História da Educação, v.11, n.1, p. 93105, jan./jun. 2012.

PERES, Eliane. Viagens e passeios familiares e escolares registrados em cadernos de alunos (1957-2015). Revista Brasileira de Pesquisa (Auto)Biográfica, Salvador, v. 02, n. 05, p. 290-309, maio/ago. 2017.

PERROT, Michelle. Práticas da memória feminina. Revista Brasileira de História. São Paulo. v.9, n.18, p.9-18, ago.89/set. 89.

RANUM, Orest. Os refúgios da intimidade. In: CHARTIER, Roger (org.). História da Vida Privada 3: da Renascença ao Século das Luzes; trad. Hildegard Feist. São Paulo: Companhia das Letras (Companhia de Bolso), 2009. p. 211-262.

THIES, Vania Grim. Arando a terra, registrando a vida: os sentidos da escrita de diários na vida de dois agricultores. 2008. 115 f. Dissertação (Mestrado em Educação) - Faculdade de Educação/FaE - Universidade Federal de Pelotas/UFPEL, Pelotas. 2008.

THIES, Vania Grim. O autor-criador e o(s) outro(s): a estética da vida na escrita de diários de irmãos agricultores. 2013. 182 f. Tese (Doutorado em Educação) - Faculdade de Educação/FaE - Universidade Federal de Pelotas/UFPEL, Pelotas. 2008.

THIES, Vania Grim; PERES, Eliane. O livro de contas do Soldado 834: contribuições à história da cultura escrita. In: Revista do Instituto Histórico e Geográfico de Sergipe. Instituto Histórico e Geográfico de Sergipe. Aracaju, Sergipe. No 47, volume 02, 2017.

VIÑAO FRAGO, Antonio. Os cadernos escolares como fonte histórica: aspectos metodológicos e historiográficos. In: MIGNOT, Ana Chrystina Venancio (Org.). Cadernos à vista: escola memória e cultura escrita. Rio de Janeiro: UERJ, 2008, p. 15-28.

VIÑAO FRAGO, Antonio. Leer y escribir: historia de dos prátcticas 
culturales.México: Fundación Voces y Vuelos, 1999.

WEIDUSCHADT, P. O Sínodo de Missouri e a educação pomerana em Pelotas e São Lourenço do Sul nas primeiras décadas do século XX: identidade e cultura escolar. 2007. 253 f. Dissertação (Mestrado em Educação) Faculdade de Educação/FaE, Universidade Federal de Pelotas, Pelotas, 2007.

WEIDUSCHADT, P. TAMBARA, E. O Sínodo de Missouri e o seminário teológico-pedagógico em são Lourenço do Sul- RS (1903-1905). Revista HISTEDBR On-line. Campinas, n.48, p. 199-224 Dez. 2012.

VANIA GRIM THIES possui graduação em Pedagogia (UFPel, 2004), especialização em Alfabetização e Letramento (UFPel, 2005), Mestrado em Educação (UFPel, 2008) e Doutorado em Educação (UFPel, 2013). É professora da Universidade Federal de Pelotas atuando no Departamento de Ensino da Faculdade de Educação e no Programa de Pós-Graduação em Educação (PPGE/ Fae/UFPEL). Coordenadora do centro de memória e pesquisa História da Alfabetização, Leitura, Escrita e dos Livros Escolares (Hisales). Coordenadora adjunta do grupo de pesquisa Hisales. Integrante do Grupo de Pesquisa Arquivos Pessoais, Patrimônio e Educação (UFRGS).

E-mail: vaniagrim@gmail.com

(i) http://orcid.org/0000-0002-6169-067X

Recebido em: 15 de dezembro de 2019

Aprovado em: 10 de janeiro de 2020

Associação Sul-Rio-Grandense de Pesquisadores em História da Educação - Asphe Artigo de acesso aberto distribuído nos termos de licença Creative Commons. 